A P Joseph, Dr F A Khan, Dr D A Harrington, Dr K E Roberts, Dr P T Y Wong, and Mrs Lynn George of Victoria Health Centre, Smethwick.

\footnotetext{
1 Wannamethee G, Shaper AG. Physical activity and stroke in middle aged British men. BMf 1992;304:597-601.

2 Dyken ML, Wolf PA, Barnett HJM, Bergan J, Hass WK, Kannel WB, et al. Risk factors in stroke: a statement for physicians by the subcommittee on risk factors and stroke of the Stroke Council. Stroke 1984;15:1105-11.

3 Royal College of Physicians Working Party. Stroke-towards better management. London: Royal College of Physicians, 1989.

4 Royal College of Physicians. Medical aspects of exercise. Benefits and risks. London: Royal College of Physicians, 1991.

5 Leon AS, Connett J, Jacobs DR, Rauramaa R. Leisure-time physical activity levels and risk of coronary heart disease and death: the multiple risk factor levels and risk of coronary heart disease and

6 Nelson L, Jennings GL, Elser MD, Korner PI. Effects of changing levels of physical activity on blood pressure and haemodynamics in essential physical activity on blood pressure and haemodynamics in essential

Shaper AG, Wannamethee G. Physical activity and ischaemic heart disease in middle-aged British men. Br Heart f 1991;66:384-94.

8 Paffenbarger RS, Wing AL. Characteristics in youth predisposing to fatal stroke in later years. Lancet 1967;i:753-4.

Paffenbarger RS, Wing AL. Chronic disease in former college students: early precursors of non-fatal stroke. Am f Epidemiol 1971;94:524-30.

10 Shinton R. Sagar G, Beevers G. The relation of alcohol consumption to cardiovascular risk factors and stroke. The west Birmingham stroke project. INeurol Neurosurg Psychiatry 1993;56:458-62.

11 World Health Organisation. Cerebrovascular diseases-prevention, treatment and rehabilitation. Technical repont series no. 469. Geneva: WHO, 1971.

2 Weiner JS, Lourie JA. Human Biology: a guide to field methods. IBP Handbook No. 9. Oxford: Blackwell Scientific Publications, 1969.

3 EGRET. Reference manual. Seattle: Statistics and Epidemiology Research Corporation, 1990.

14 Breslow NE, Day NE. Statistical methods in cancer research. Vol 1. The analysis
}

of case-control studies. Lyon: International Agency for Research on Cancer, 1980.

15 Shinton RA. Lifestyle and the risk of stroke [MD thesis]. Cambridge: University of Cambridge, 1992.

16 Blair SN, Dowda M, Pate RR, Kronenfeld J, Howe HG, Parker G, et al. Reliability of long-term recall of participation in physical activity by middle aged men and women. Am $\mathcal{F}$ Epidemiol 1991;133:266-75.

17 Paffenbarger RS, Brand RJ, Sholtz RI, Jung DL. Energy expenditure, cigarette smoking, and blood pressure level as related to death from specific diseases. Am $\mathcal{F}$ Epidemiol 1978;108:12-8.

18 Kannel WB, Sorlie P. Some health benefits of physical activity. Arch Intern Med 1979;139:857-61.

19 Salonen JT, Puska P, Tuomilehto J. Physical activity and risk of myocardial infarction, cerebral stroke and death. Am f Epidemiol 1982;115:526-37.

20 Herman B, Schmitz PIM, Leyten ACM, Van Luijk JH, Frenken CWGM, Op de Coul AAW, et al. Multivariate logistic analysis of risk factors for stroke in Tilburg, The Netherlands. Am $\mathcal{F}$ Epidemiol 1983;118:514-25.

21 Paffenbarger RS, Hyde RT, Wing AL, Steinmetz CH. A natural history of athleticism and cardiovascular health. ҰAMA 1984;252:491-5.

22 Lapidus L, Bengtsson C. Socioeconomic factors and physical activity in relation to cardiovascular disease and death. A 12 year follow up of participants in a population study of women in Gothenberg, Sweden. $B$ Heart f 1986;55:295-301.

23 Paganini-Hill A, Ross RK, Henderson BE. Postmenopausal oestrogen treatment and stroke: a prospective study. BMF 1988;297:519-22.

24 Folsom AR, Prineas RJ, Kaye SA, Munger RG. Incidence of hypertension and stroke in relation to body fat distribution and other risk factors in older women. Stroke 1990;21:701-6.

25 Young and unfit? [editorial]. Lancet 1992;340:19-20.

26 Helmrich SP, Ragland DR, Leung RW, Paffenbarger RS. Physical activity and reduced occurrence of non-insulin-dependent diabetes mellitus. $N$ Engl fMed 1991;325:147-52.

27 Manson JE, Rimm EB, Stampfer MJ, Colditz GA, Willett WC, Krolewsk AS, et al. Physical activity and incidence of non-insulin-dependent diabetes mellitus in women. Lancet 1991;338:774-8.

(Accepted 21 May 1993)

\title{
Psychological distress in pregnancy and preterm delivery
}

\author{
Morten Hedegaard, Tine Brink Henriksen, Svend Sabroe, Niels Jørgen Secher
}

Abstract

Objective-To investigate if psychological distress during pregnancy is associated with increased risk of preterm delivery.

Design-Prospective, population based, follow up study with repeated measures of psychological distress (general health questionnaire), based on the use of questionnaires.

Setting-Antenatal care clinic and delivery ward, Aarhus University Hospital, Denmark.

Subjects -8719 women with singleton pregnancies attending antenatal care for the initial visit between 1 August 1989 and 30 September 1991; 5872 women $(67 \%)$ completed all questionnaires.

Main outcome measure-Preterm delivery. Estimation of gestational age at delivery was mainly based on early ultrasound measurements.

Results-In 197 cases (3.6\%) the woman delivered prematurely (less than 259 days). A dose-response relation between psychological distress in the 30th week of pregnancy and risk of preterm delivery was found, but distress measured in the 16th week was not related to preterm delivery. Control of confounding was secured by the use of multivariate logistic regression models. Relative risk for preterm delivery was $1.22(95 \%$ confidence interval 0.84 to $1 \cdot 79)$ for moderate distress and $1.75(1.20$ to 2.54$)$ for high distress in comparison to low distress.

Conclusions-Psychological distress later in pregnancy is associated with an increased risk of preterm delivery. Future interventional studies should focus on ways of lowering psychological distress in late pregnancy.

\section{Introduction}

Low birth weight, which is the result of preterm delivery or fetal growth retardation, is an important determinant of the newborn's health. ${ }^{1}$ Preterm delivery, defined as delivery before 259 days' gestation, ${ }^{2}$ is the obstetric complication with the largest impact on perinatal mortality, ${ }^{3}$ and is a major determinant of neonatal morbidity, ${ }^{4}$ and neurological and neurobehavioural sequelae. ${ }^{5}$

Advances in neonatal intensive care have improved the chances of survival of the preterm infant, ${ }^{6}$ but the rate of preterm delivery remains unchanged. Problems associated with preterm delivery will not be solved by therapeutic interventions alone, and emphasis has been placed on the role of prevention.

The aetiology of preterm delivery is largely unknown, but a few causes have been identified: mother's education and socioeconomic status, smoking, low weight and height before pregnancy, young age. Stress has been hypothesised as a risk factor for preterm delivery, ${ }^{8}$ perhaps by inducing release of oxytocin. ${ }^{9}$

The aim of this prospective cohort study was to evalute the association between psychological distress and preterm delivery, and if such an association was present to test the existence of a dose-response relation. Other determinants of preterm delivey were adjusted for in the analysis by using multivariate statistical models.

\section{Methods}

From 1 August 1989 to 30 September 1991, a cohort of pregnant women was established at the Department of Obstetrics at Arhus University Hospital. Women living in a well defined geographical area with a population of about 250000 are referred to the department, which is the only maternity unit in the city. A few women with specific pregnancy complications, such as diabetes or isoimmunisation, are referred to the department from a larger geographical area.

Danish speaking women attending the antenatal programme for the initial examination were eligible for inclusion in the study. In Denmark more than $97 \%$ of all pregnant women attend an antenatal programme. After exclusion of women with twin

Dr Hedegaard. 
gestations or miscarriages, the cohort comprised 8719 women.

At enrolment in the 16 th week of gestation the women were asked to fill in a basic questionnaire about medical and obstetric history, menstrual data, etc, and a second questionnaire about psychological distress and other psychosocial factors (table I). The questionnaires were completed at home. Two reminders were mailed to non-responders. The basic questionnaire was also used by the physicians as the basis for the pregnant woman's record. Shortly before the 30th week of pregnancy the women who had answered the second questionnaire received a third questionnaire largely identical to the second. One reminder was mailed to non-responders. Of the 8719 women in the cohort 8554 women $(98 \%)$ completed the basic questionnaire, 7014 women $(80 \%)$ completed the basic and the second questionnaires, and 5872 women (67\%) completed all the questionnaires. To test the hypothesis of the study data from the second and the third questionnaires were required, and the primary analysis was therefore conducted for the group of 5872 women who answered the three questionnaires. Thirty nine of these women $(0.7 \%)$ were lost from follow up.

Immediately after delivery the attending midwife filled in a specific registration form. In this way, information about the baby (weight, length, Apgar score, etc) and obstetric and medical complications during pregnancy were collected. The obstetric data were validated by a research midwife reviewing the hospital records. Information about parturition and the baby was also provided for women who gave birth in delivery wards elsewhere $(n=1017)$.

The midwives and physicians caring for the women during pregnancy and labour did not have access to the information in the second and third questionnaires.

The principal measure of psychological distress was the 30 item version of the general health questionnaire, ${ }^{10}$ a screening instrument designed for use in general population surveys. The scores indicate the severity of psychological disturbance on a continuum. The content and concurrent validity of this questionnaire have been tested in a Danish population. ${ }^{112}$ In the present study the reliability of the questionnaire was found to be high (Cronbach's $\alpha>0.90$ ). ${ }^{13}$

Each item on the general health questionnaire was coded with the scores 0 to 3 ( $0=$ low stress, $3=$ high stress). The total score, which could range from 0 to 90 , was calculated as the sum of the single items. The mean score in the 16th week was 23.2 (SD 8.9) and in the 30 th week it was $23.5(9.4)$. In some of the logistic regression models, the scores on the general health questionnaire were grouped to facilitate the interpretation of results (fig 1): low (score $\leqslant 23$ ), moderate (24-30), and high ( $\geqslant 31$ ). A score of 24 was chosen as the cut off point as this included scores above the mean, and a cut off point of 31 divided the scores above

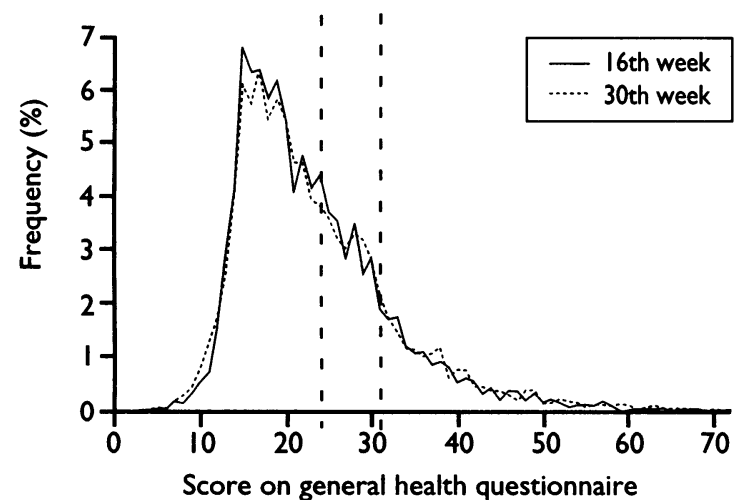

FIG 1-Frequency distribution of the scores on general health questionnaire (continuous) in 16th and 30th week of gestation in 5873 Danish women. Vertical lines show low, medium, and high categories
TABLE I-Contents of questionnaires administered during pregnancy

\begin{tabular}{|c|c|c|c|}
\hline & Basic & $\begin{array}{c}16 \\
\text { Weeks }\end{array}$ & $\begin{array}{c}30 \\
\text { Weeks }\end{array}$ \\
\hline Medical history & $\checkmark$ & & \\
\hline Obstetrical history & $\checkmark$ & & \\
\hline Treatment of infertility & $\checkmark$ & & \\
\hline Menstrual history & $\checkmark$ & & \\
\hline Vaginal bleeding during present pregnancy & $\checkmark$ & & $\checkmark$ \\
\hline $\begin{array}{l}\text { Medical treatment before or during present } \\
\text { pregnancy }\end{array}$ & $\sqrt{ }$ & & $\checkmark$ \\
\hline Urogenital infections in present pregnancy & $\checkmark$ & & $\sqrt{ }$ \\
\hline $\begin{array}{l}\text { Mother's age, height, and prepregnant weight; } \\
\text { father's age }\end{array}$ & $\sqrt{ }$ & & \\
\hline Smoking habits before and during present pregnancy & $\checkmark$ & & $\checkmark$ \\
\hline Alcohol consumption & $\checkmark$ & & $\sqrt{ }$ \\
\hline Drug misuse & $\checkmark$ & & \\
\hline General health questionnaire ( 30 items) & & $\checkmark$ & $\sqrt{ }$ \\
\hline Stressful life events ( 28 items) & & $\checkmark$ & $\checkmark$ \\
\hline Social network ( 9 items) & & $\checkmark$ & $\mathrm{v}$ \\
\hline Level of theoretical and practical education & & & \\
\hline Mother & & $\checkmark$ & \\
\hline Father & & $\checkmark$ & \\
\hline Occupational status: & & & \\
\hline Mother & & $\checkmark$ & $\checkmark$ \\
\hline Father & & $\sqrt{ }$ & \\
\hline Physical job strain & & $\checkmark$ & $\checkmark$ \\
\hline Psychological job strain (Karasek, 48 item) & & $\checkmark$ & $\sqrt{ }$ \\
\hline Chemical end radiological exposures & & $\checkmark$ & \\
\hline Domestic tasks & & $\checkmark$ & $\checkmark$ \\
\hline Activities during leisure time & & $\checkmark$ & $\checkmark$ \\
\hline Mother's and father's birth weight & & $\checkmark$ & \\
\hline Father's height and weight & & $\checkmark$ & \\
\hline Marital status & & $\sqrt{ }$ & \\
\hline Exposure to passive smoking & & $\checkmark$ & $\checkmark$ \\
\hline $\begin{array}{l}\text { Consumption of caffeine (coffee, tea, cola } \\
\text { beverages) }\end{array}$ & & $\sqrt{ }$ & \\
\hline
\end{tabular}

the mean into a smaller "high" and a larger "moderate" group.

In 5005 cases $(86 \%)$ gestational age at delivery was based on measurement of the fetal biparietal diameter by ultrasonography before 21 weeks' gestation. ${ }^{14}$ In 454 cases $(8 \%)$ gestational age was calculated from the date of the last menstrual period, adjusted to a cycle length of 28 days. In the remaining 374 cases $(6 \%)$, gestational age at delivery could be based only on an estimate given by the attending midwife on the birth certificate. As the accuracy of these estimates were uncertain, these 374 cases were excluded from the analysis.

Possible confounders were identified from background data (age, height, weight before pregnancy, mother's birth weight, marital status, education, employment), obstetric risk factors (parity, complications in previous pregnancies or present pregnancy), and health behaviour (smoking, diet, intake of alcohol during pregnancy).

Analysis of categorical data was based on $\chi^{2}$ test and $\chi^{2}$ test for trend. Analysis of categorical exposures in relation to continuous effects was based on one way analysis of variance, including test for linearity. ${ }^{15}$ Mean values with standard deviation are given. Multivariate analysis of dichotomous effects was based on multiple logistic regression. ${ }^{16}$ Statistical significance was defined as $p<0.05$, and $95 \%$ confidence intervals are presented.

The research protocol was approved by the regional committee for ethics in science and by the Danish committee of registers (Registertilsynet).

\section{Results}

In the group of 5459 women who completed the three questionnaires, and for whom follow up and a firm estimate of length of gestation was available, the mean (SD) duration of gestation was 281.9 (11.4) days. One hundred and ninety seven women (3.6\%) delivered prematurely.

Table II shows gestational duration in relation to basic socioeconomic and medical factors. On the basis of these findings, the women delivering prematurely could be characterised by age (below 20 years), smoking (more smokers), and complications in previous pregnancies (higher incidence of preterm 


\begin{tabular}{|c|c|c|c|c|c|c|c|}
\hline \multirow[b]{2}{*}{ Variable } & \multirow[b]{2}{*}{$\begin{array}{c}\text { No of } \\
\text { women }\end{array}$} & \multirow{2}{*}{$\begin{array}{l}\text { Mean } \\
\text { gestational age } \\
\text { at delivery } \\
\text { (days) }\end{array}$} & \multicolumn{2}{|c|}{$\mathrm{p}$ Value } & \multirow[b]{2}{*}{$\begin{array}{c}\text { No }(\%) \text { of } \\
\text { preterm } \\
\text { deliveries }\end{array}$} & \multicolumn{2}{|c|}{$\mathrm{p}$ Value } \\
\hline & & & $\begin{array}{l}\text { One way } \\
\text { analysis of } \\
\text { variance }\end{array}$ & $\begin{array}{l}\text { Test for } \\
\text { linearity }\end{array}$ & & $\chi^{2}$ test & $x^{2}$ for trend \\
\hline \multicolumn{8}{|l|}{ Age (years): } \\
\hline$\leqslant 19$ & 72 & 276.6 & $<0.001$ & 0.001 & $8(11 \cdot 1)$ & 0.004 & 0.41 \\
\hline $20-24$ & 783 & $280 \cdot 8$ & & & $26(3 \cdot 3)$ & & \\
\hline $25-29$ & 2333 & 281.9 & & & $88(3.8)$ & & \\
\hline $30-34$ & 1547 & $282 \cdot 7$ & & & $44(2 \cdot 8)$ & & \\
\hline$\geqslant 35$ & 724 & $281 \cdot 8$ & & & $31(4 \cdot 3)$ & & \\
\hline \multicolumn{8}{|l|}{ Prepregnant weight (kg): } \\
\hline$\leqslant 49$ & 297 & $280 \cdot 0$ & 0.001 & 0.02 & $15(5 \cdot 1)$ & 0.11 & 0.48 \\
\hline $50-59$ & 2226 & $281 \cdot 5$ & & & $76(3 \cdot 4)$ & & \\
\hline $60-69$ & 1975 & $282 \cdot 7$ & & & $61(3 \cdot 1)$ & & \\
\hline $70-79$ & 595 & $282 \cdot 2$ & & & $30(5 \cdot 0)$ & & \\
\hline$\geqslant 80$ & 270 & $281 \cdot 0$ & & & $12(4 \cdot 4)$ & & \\
\hline \multicolumn{8}{|l|}{ Mother's height $(\mathrm{cm})$ : } \\
\hline$\leqslant 159$ & 438 & $280 \cdot 3$ & $<0.001$ & $<0.001$ & $22(5 \cdot 0)$ & 0.19 & 0.07 \\
\hline $160-164$ & 1153 & $281 \cdot 0$ & & & $49(4 \cdot 2)$ & & \\
\hline $165-169$ & 1684 & $282 \cdot 1$ & & & $57(3 \cdot 4)$ & & \\
\hline $170-174$ & 1438 & $282 \cdot 3$ & & & $42(2.9)$ & & \\
\hline$\geqslant 175$ & 663 & $283 \cdot 2$ & & & $25(3.8)$ & & \\
\hline \multicolumn{8}{|l|}{ Smoking (cigarettes/day): } \\
\hline 0 & 3831 & 282.5 & $<0.001$ & $<0.001$ & $113(2.9)$ & $<0.001$ & $<0.001$ \\
\hline $1-4$ & 249 & $282 \cdot 1$ & & & $9(3 \cdot 6)$ & & \\
\hline 5.9 & 473 & $281 \cdot 0$ & & & $21(4 \cdot 4)$ & & \\
\hline $10-14$ & 538 & $280 \cdot 4$ & & & $28(5 \cdot 2)$ & & \\
\hline$\geqslant 15$ & 368 & $279 \cdot 0$ & & & $26(7 \cdot 1)$ & & \\
\hline \multicolumn{8}{|l|}{ Married status: } \\
\hline Married & 2820 & $282 \cdot 0$ & 0.61 & & $89(3 \cdot 2)$ & $0 \cdot 19$ & \\
\hline Cohabiting & 2422 & 281.8 & & & $98(4 \cdot 0)$ & & \\
\hline Living alone & 182 & $281 \cdot 2$ & & & $8(4 \cdot 4)$ & & \\
\hline \multicolumn{8}{|l|}{ Education (years): } \\
\hline$\leqslant 9$ & 472 & $280 \cdot 8$ & $<0.001$ & $<0.001$ & $23(4.9)$ & $0 \cdot 11$ & 0.04 \\
\hline $10-11$ & 1627 & $281 \cdot 2$ & & & $65(4 \cdot 0)$ & & \\
\hline$\geqslant 12$ & 3160 & $282 \cdot 5$ & & & $101(3 \cdot 2)$ & & \\
\hline \multicolumn{8}{|l|}{ Parity: } \\
\hline 0 & 2946 & $282 \cdot 1$ & 0.02 & 0.02 & $112(3 \cdot 8)$ & 0.57 & 0.67 \\
\hline 1 & 1783 & 282.0 & & & $60(3.4)$ & & \\
\hline 2 & 585 & $281 \cdot 3$ & & & $18(3 \cdot 1)$ & & \\
\hline$\geqslant 3$ & 136 & $279 \cdot 3$ & & & $7(5 \cdot 1)$ & & \\
\hline \multirow{5}{*}{$\begin{array}{l}\text { Previous deliveries: } \\
\text { Primparous } \\
\text { Previous term delivery } \\
\text { Preterm delivery or low birthweight } \\
\text { infant }\end{array}$} & & & & & & & \\
\hline & 2946 & $282 \cdot 1$ & $<0.001$ & & $112(3 \cdot 8)$ & $<0.001$ & \\
\hline & 2256 & $282 \cdot 4$ & & & $62(2 \cdot 7)$ & & \\
\hline & & & & & $23(9 \cdot 3)$ & & \\
\hline & 248 & $275 \cdot 4$ & & & & & \\
\hline
\end{tabular}

delivery and birth weight $<2500 \mathrm{~g}$ ). Shortened duration of gestation was associated with the same factors as well as with low maternal height and prepregnant weight, shorter education, and high parity. Furthermore, women delivering prematurely had a higher incidence of unemployment and were less often students. During pregnancy a greater proportion of women with preterm delivery experienced vaginal bleeding and hypertension (data not shown). As some women did not want to answer some questions, and as some of the answers were conflicting, the completeness of data in table II varies.

Table III shows the relation between scores on the general health questionnaire and outcome. In the 16th week, high distress was associated with a nonsignificant increase in risk of preterm delivery. Data

TABLE III-Relation of general health questionnaire scores to term or preterm delivery. Values are numbers (percentages) unless otherwise indicated

\begin{tabular}{|c|c|c|c|}
\hline Variable & $\begin{array}{l}\text { Preterm } \\
\text { delivery }\end{array}$ & $\begin{array}{c}\text { Term } \\
\text { delivery }\end{array}$ & $\mathrm{p}$ Value \\
\hline \multicolumn{4}{|c|}{ Mean (SD) continuous score: } \\
\hline At 16 weeks & $23 \cdot 7(9 \cdot 2)$ & $23.1(8.9)$ & $0.35 t$ \\
\hline At 30 weeks & $26 \cdot 0(11 \cdot 0)$ & $23 \cdot 3(9 \cdot 3)$ & $0.000 \dagger$ \\
\hline \multicolumn{4}{|l|}{ Trichotomised score: } \\
\hline \multicolumn{4}{|l|}{ At 16 weeks: } \\
\hline Low $(0.23)$ & $107(3 \cdot 4)$ & 3079 & $0.49(0.37) \dagger$ \\
\hline Moderate (24.30) & $50(4 \cdot 1)$ & $1167 \ddagger$ & \\
\hline High $(31-90)$ & $32(3 \cdot 8)$ & $816 \ddagger$ & \\
\hline \multicolumn{4}{|l|}{ At 30 weeks: } \\
\hline Low $(0-23)$ & $91(2.9)$ & 3068 & $0.001(0.002) \dagger$ \\
\hline Moderate (24-30) & $46(3.8)$ & $1164 \ddagger$ & \\
\hline High $(31-90)$ & $50(5 \cdot 4)$ & $873 \ddagger$ & \\
\hline
\end{tabular}

\section{${ }^{\star} t$ Test.}

$\dagger$ Test for difference between preterm group and not-preterm group: $\chi^{2}$ test (test for trend).

$¥$ Relative risk for preterm delivery 1.29 and 1.13 in the 16 th week, and 1.25 and 1.93 in the 30th week (moderate and high distress compared to low distress).

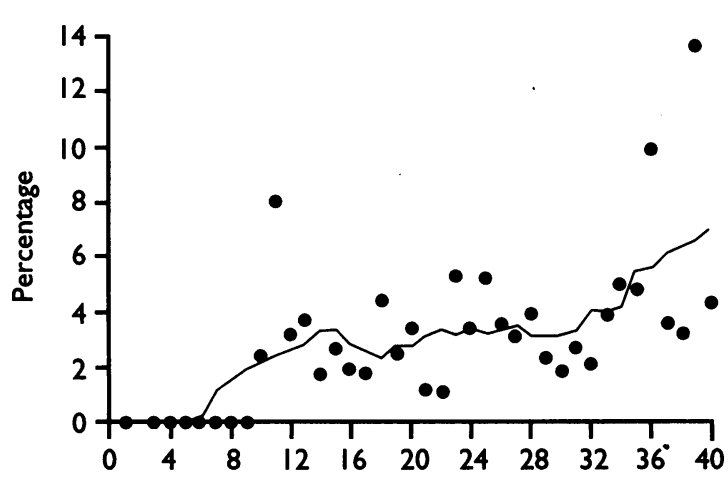

Score on general health questionnaire at 30 weeks

FIG 2-Percentage of women with preterm delivery by score on general health questionnaire at 30 weeks. Curve smoothed by moving average (overfour steps)

from the 30th week showed a strong association between distress and preterm delivery, irrespective of whether general health questionnaire scores were analysed as a continuous or a trichotomised variable. Figure 2 shows the risk of preterm delivery in relation to general health questionnaire scores, with the information from adjacent general health questionnaire values plotted as a moving average to display a continuous description of the association. The risk of preterm delivery rose gradually from about $1 \%$ for low scores to about $6 \%$ for high scores in a dose-response relation. Figures 3 and 4 show the percentage of women delivering in the individual weeks of gestation in relation to category of general health questionnaire score in the 30th week.

Scores on the general health questionnaire were also associated with other factors related to preterm delivery, such as smoking. As the association between 


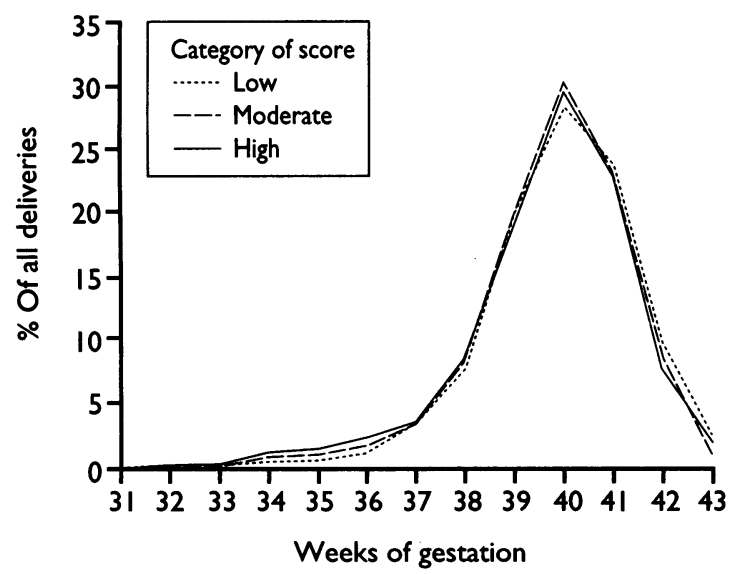

FIG 3-Relation of general health questionnaire score at 30 weeks to gestational age at delivery

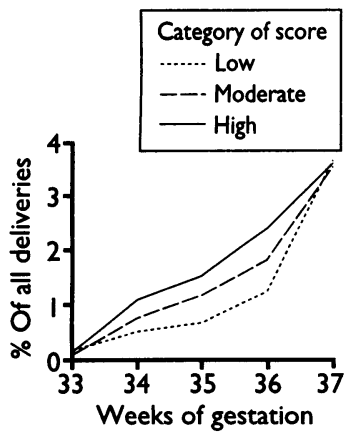

FIG 4-Preterm deliveries by category of general health questionnaire score at 30 weeks' gestation
A case-control design can use smaller numbers as only a few controls are sampled in comparison to follow up studies, and the case-control design has often been used. ${ }^{192-24}$ This strategy is, however, predisposed to information bias (selective recall) as data about psychosocial factors during pregnancy are collected after delivery.

A follow up study meets some of the criticisms of earlier studies, but this design has some methodological limitations as it is mainly possible to test what has been called the accumulation hypothesis in contrast to the immediate causation hypothesis. ${ }^{25}$ In our study, the final information about distress was given in the 30th week of pregnancy, and a state of distress after this point was not registered. Acute distress after the 30th week of pregnancy, though not recognised in our study, might cause preterm delivery. This bias cannot, however, explain the association actually observed.

We used a validated scale to measure distress-the general health questionnaire, which is regarded as a leading example of this type of health measurement ${ }^{26}$ and has previously been used in studies of pregnant women. ${ }^{27}$ Other studies that used very indirect measures of exposure, such as job title, did not find any relation between stress and risk of preterm delivery, ${ }^{28} 29$ but the validity of measuring stress in this way is open to question.

We investigated the causes of a very specific type of adverse outcome: delivery before 259 days' gestation. Previous studies have made combinations of pregnancy complications the outcome of interest-the catch all approach, ${ }^{22} 30$ with complication rates of up to $50 \% .^{22}$ It is therefore difficult to draw any clinical implications from these studies. Furthermore, there is no evidence that different obstetric complications share the same aetiology. A recent study has shown that different categories of low birth weight (preterm delivery and intrauterine growth retardation) have dissimilar aetiology. ${ }^{24}$ It thus seems essential to regard different obstetric complications as single entities. Amalgamating complications with different or contradictory causation might even obscure detection of causes.

Many factors are believed or known to influence the course of pregnancy, and studies must control possible confounding of associations. For this reason we applied multivariate logistic regression, where possible, simultaneously to control for several confounders. We found that the point estimates of the crude models (table III) and of multivariate models (table IV) were similar, and hence we did not find strong evidence of confounding in our data.

Identification of preterm delivery hinges on estimation of gestational age at delivery. In the present study it was possible to base the gestational age estimate on early ultrasound measurement in the large majority of women $(86 \%)$. This method has been regarded as the most valid way of measuring gestational duration. ${ }^{31}$

Basic data were collected for almost all of the target population (98\%), but some women did not answer the questionnaire in the 16 th week and additional women did not answer the questionnaire in the 30th week. Asked about the reason for declining to participate in the 16 th week, most women mentioned the length of the questionnaire or worry about being registered by personal identification numbers. Women who answered the second questionnaire but not the third had a higher incidence of preterm delivery and shorter mean duration of gestation than other women, which follows from the fact that some women were unable to answer the questionnaire at 30 weeks because of very preterm delivery. The general health questionnaire scores of women who filled in all questionnaires were highly correlated between the 16 th and the 30 th week $(r=0.55)$. In accordance with the other findings in the
This study includes close to 6000 women, wher most previous studies were based on small sample sizes (fewer than 250 women). ${ }^{1920}$ Negative findings in small studies are difficult to interpret as results might be explained by a lack of statistical power. ${ }^{21}$ 
study, women who answered the second questionnaire but not the third had higher general health questionnaire scores in the 16th week than women who answered all questionnaires. Although it is thus unlikely, selection bias could be introduced by the non-response: if non-responders in the 30th week (with a high incidence of preterm delivery) had low scores on the general health questionnaire the association of the study might be explained by bias (differentiated non-response). Assuming the extreme situation, in which all non-responders had low general health questionnaire scores, we conducted additional analyses. In this hypothetical example, the risk associated with high scores on the general health questionnaire remained (adjusted relative risk $1.21 \quad(0.88$ to 1.67)).

We found a distinct association between distress in the 30th week of pregnancy and risk of preterm delivery, but distress in the 16th week was not significantly associated with risk of preterm delivery. The general health questionnaire is a "here and now" assessment and does not seek to integrate distress over time. The absence of association between the measurement in the 16th week and preterm delivery is therefore consistent. The findings seem to depict a change in vulnerability during pregnancy.

Increased scores on the general health questionnaire may reflect complications in previous pregnancies (such as preterm delivery) or in the actual pregnancy (such as early vaginal bleeding or hypertension), factors known to increase risk of preterm delivery. If so, the general health questionnaire should be regarded as merely an indirect measure (proxy variable) of complications (previous or actual). To test this hypothesis, the relation between scores at 30 weeks and preterm delivery was tested among the $\mathbf{5 2 8 3}$ women without complications in their previous or current pregnancies (590 women with complicated pregnancies were excluded). The adjusted relative risk for preterm delivery of the moderate and high categories were $1.31(0.83$ to 2.06$)$ and $1.92(1.23$ to 3.00$)$, comparable to the findings among all women. Consequently, we found no evidence that the associations were explained by past or present complications.

A large prospective cohort study using validated scales, confounder control, and a well defined outcome measure was conducted by Brooke et al, who studied the relation between several psychosocial factors, including the general health questionnaire, and birth weight in 1800 pregnancies. ${ }^{27}$ As gestational age was controlled for in the analysis, the results were presented in terms of fetal growth. When smoking was controlled for, no relation with general health questionnaire scores was found, but the relation with preterm delivery was not investigated, and to our knowledge no previous studies concerning preterm delivery have met all components of validity.

The findings in our study are primarily of interest if intervention is possible. A few studies have pursued this issue, using social support as the intervention. ${ }^{32-35}$

\section{Clinical implications}

- Preterm delivery occurs in about $5 \%$ of all deliveries and is closely associated with perinatal mortality and morbidity

- Psychological distress later in pregnancybut not early in pregnancy-is related to increased risk of preterm delivery

- Future intervention studies should be conducted within groups of women with high levels of psychological distress
The results did not show any reduction in risk of preterm delivery, but more research is needed. If distress is the relevant exposure then interventions must be found to reduce distress. If distress is not lowered by increased social support (increased number of visits by family workers or midwives) other interventional strategies are needed. To show an effect of intervention, future studies should perhaps be restricted to women with high levels of psychological distress, and low social support at study entry, rather than women with a statistically high risk of preterm delivery, such as women who have previously delivered a low birthweight infant. ${ }^{30}$

We thank the staff at the Perinatal Epidemiological Research Unit and at the Antenatal Care Clinic at the University Hospital in Aarhus for their assistance during data collection and processing, the midwives of the maternity ward for their contribution to the data collection, Per Bech for fruitful discussions concerning the design of the study, and Adrian Grant and Diana Elbourne for valuable comments on a previous draft.

The project was supported by Danish Medical Research Council (12-7806, 12-9181), Sygekassernes Helsefond (11/274-88, 11/98-90), the research fund of the University of Aarhus (105655), 12-91-81), and Egmont H Petersens Fond (8.3.1.-1361).

1 McCormick MC. The contribution of low birth weight to infant mortality and childhood morbidity. N Engl F Med 1985;312:82-90.

2 World Health Organisation. Recommended definitions, terminology and format for statistical tables related to the perinatal period and use of a new certificate for cause of perinatal deaths. Acta Obstet Gynecol Scand 1977;56: 247-53.

3 Verloove-Vanhorick SP, Verwey RA, Brand R, Gravenhorst JB, Keirse MJ, et al. Neonatal mortality risk in relation to gestational age and birthweight. Results of a national survey of preterm and very-low-birthweight infants in the Netherlands. Lancet 1986;: :55-7.

4 Hakulinen A, Heinonen K, Jokela V, Launiala K. Prematurity-associated morbidity during the first two years of life. A population-based study. Acta Paediatr Scand 1988;77:340-8.

5 Hadders-Algra M, Huisjes HJ, Touwen BC. Perinatal risk factors and minor neurological dysfunction: significance for behaviour and school achievement at nine years. Dev Med Child Neurol 1988;30:482-91.

6 Heinonen K, Hakulinen A, Jokela V. Survival of the smallest. Time trends and determinants of mortality in a very preterm population during the $1980 \mathrm{~s}$. Lancet 1988;ii:204-7.

7 Hoffman HJ, Bakketeig LS. Risk factors associated with the occurrence of preterm birth. Clin Obstet Gynecol 1984;27:539-52.

8 Kramer MS. Determinants of low birth weight: methodological assessment and meta-analysis. Bull World Health Organ 1987;65:663-737.

9 Lang RE, Heil JWE, Ganten D, Hermann K, Unger T, Rasher W. Oxytocin unlike vasopressin is a stress hormone in the rat. Neuroendocrinology 1983;37:314-6.

10 Goldberg DP. The detection of psychiatric illness by questionnaire. London: Oxford University Press, 1972. (Maudsley monographs No 21.)

11 Bech P. Quality of life in psychosomatic research. A psychosomatic model. Psychopathology 1987;20:169-70.

12 Bech P, Loldrup D, Garre K, Rasmussen K. Erenlund Jensen H. Measurement of the quality of life in assessing therapeutic effects in essential hypertension. Methodologic aspects. Ugeskr Laeger 1990;152:383-6.

13 Crohnbach LJ. Essentials of psychological testing. New York: Harper and Row, 1990.

14 Eriksen PS, Secher NJ, Weis-Bentzon M. Normal growth of the fetal biparietal diameter and the abdominal diameter in a longitudinal study. An evaluation of the two parameters in predicting fetal weight. Acta Obstet Gynecol Scand 1985;64:65-70.

15 Armitage P, Berry G. Statistical methods in medical research. Oxford: Blackwell Scientific, 1987.

16 Hosmer D, Lemeshow S. Applied logistic regression. New York: Wiley, 1989.

17 Greenland S. Modelling and variable selection in epidemiologic analysis. Am I Public Health 1978;79:340-9.

18 McDonald RL. The role of emotional factors in obstetric complications: a review. Psychosom Med 1968;30:222-37.

19 Williams CC, Williams A, Griswold MJ, Holmes TH. Pregnancy and life change. F Psychosom Res 1975;19:123-9.

20 Newton RW, Hunt LP. Psychosocial stress in pregnancy and its relation to low birth weight. BMF 1984;288:1191-4.

21 Stein A, Campbell EA, Day A, McPherson K, Cooper PJ. Social adversity, low birth weight, and preterm delivery. BMF 1987;295:291-3.

22 Nuckolls KB, Cassel J, Kaplan BH. Psychosocial assets, life crisis and the prognosis of pregnancy. Am $\mathcal{F}$ Epidemiol 1972;95:431-41.

23 Berkowitz GS, Kasl SV. The role of psychosocial factors in spontaneous preterm delivery. $\mathcal{F}$ Psychosom Res 1983;27:283-90.

24 Mutale T, Creed F, Maresh M, Hunt $L$. Life events and low birthweightanalysis by infants preterm and small for gestational age. $\mathrm{Br} \mathcal{F}$ Obstet Gynaecol 1991;98:166-72.

25 Omer H, Everly GSJ. Psychological factors in preterm labor: critical review and theoretical synthesis. Am F Psychiatry 1988;145:1507-13.

26 McDowell J, Newell C. Measuring health: a guide to rating scales and questionnaires. New York: Oxford University Press, 1987.

27 Brooke OG, Anderson HR, Bland JM, Peacock JL, Stewart CM. Effects on birth weight of smoking, alcohol, caffeine, socioeconomic factors, and psychosocial stress. BMF 1989;298:795-801.

28 Homer CJ, James SA, Siegel E. Work-related psychosocial stress and risk of preterm, low birthweight delivery. Am ₹ Public Health 1990;80:173-7. 
29 Klebanoff MA, Shiono PH, Rhoads GG. Outcomes of pregnancy in a national sample of resident physicians. N Engl f Med 1990;323:1040-5.

30 Beck NC Siegel LJ, Davidson NP, Kommer S, Bre preparation, anxiety and

31 Grennert I Persson PH, Gennser G. Benefits of ultrasonic screening of a pregnant population. Acta Obstet Gynecol Scand Suppl 1978;78(suppl):5-14.

32 Spencer B, Thomas H, Morris J. A randomised controlled trial of the provision of a social support service during pregnancy: the South Manchester Family Worker Project. Br F Obstet Gynaecol 1989;96:281-8.

\section{Microalbuminuria in chronic obstructive lung disease}

\section{R Wilkinson, J S Milledge, M J Landon}

Northwick Park Hospital,

HA1 3UJ

R Wilkinson, registrar

J S Milledge, consultant physician

\section{MRC Clinical Research Centre, Harrow, Middlesex HA1 3UJ}

M J Landon, scientific staff

\section{Correspondence to:}

Dr Milledge.

$B M{ }^{9} 1993 ; 307: 239$ Harrow, Middlesex

Changes in renal function have been reported in chronic obstructive lung disease ${ }^{1}$ but not proteinuria. We describe a heterogeneous group of patients with chronic obstructive lung disease who were found to have microalbuminuria.

\section{Patients, methods, and results}

Twenty two inpatients with chronic obstructive lung disease provided a clean catch midstream specimen of urine. Twenty normal healthy volunteers matched for sex (two women in each group) and age (within two years) provided control samples. None had any medical history of renal disease.

Forced expiratory volume in one second and forced vital capacity were measured by standard spirometric methods and arterial blood gas values by Instrumentation Laboratory (UK) Blood Gas Analyser 3. Albumin was measured with pyrogallol red molybdate. $\gamma$-Glutamyltransferase, $\quad \beta$ - $N$-acetylglucosaminidase, and lysozyme values were measured by using commercially available substrates. Results of the urine analyses were expressed per mmol creatinine. As the results were not normally distributed, log transformed data were used for analysis. Two sample $t$ tests were used to compare the chronic obstructive lung disease and control groups, and the linear association between variables was assessed with Pearson correlation coefficients.

Patients with cor pulmonale Mean and SD - - - - Upper limit of reference range

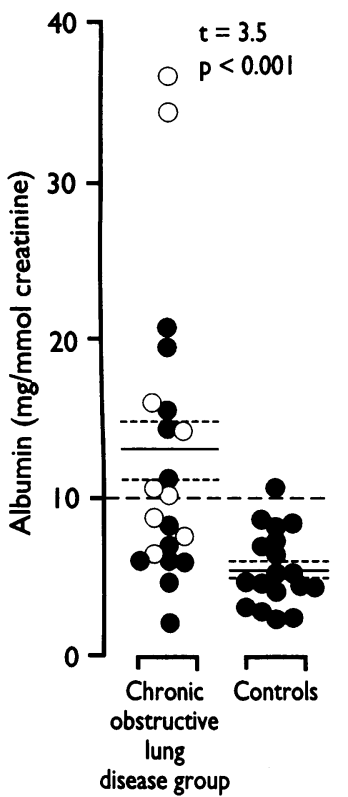

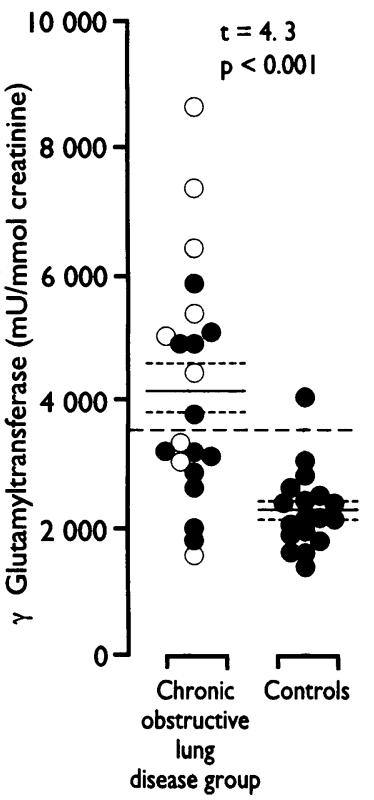

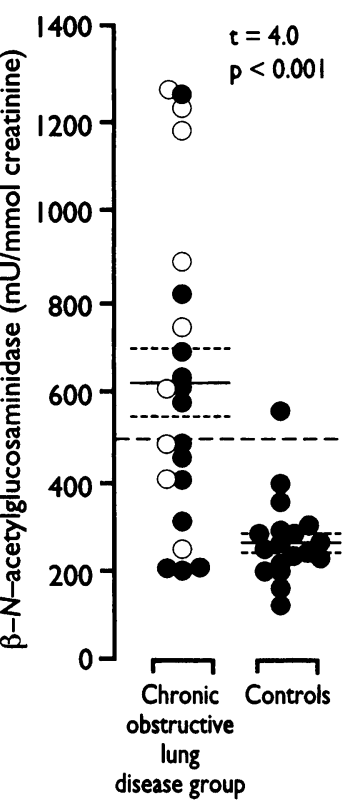

Urinary albumin $\gamma$-glutamyltransferase, and $\beta-N$-acetylglycosaminidase in patients with chronic obstructive lung disease and controls
33 Oakley A, Rajan L, Grant A. Social support and pregnancy outcome. Br F Obstet Gynaecol 1990;97:155-62.

34 Chalmers I, ed. Oxford database of perinatal trials. Oxford: Oxford University Press, 1988.

35 Vilar J, Farnot U, Barros F, Victora C, Langer A, Belizan JM. A randomized trial of psychosocial support during high-risk pregnancies. $N$ Engl $f$ Med 1992;327:1266-71.

(Accepted 13 May 1993)

The average age of the patients with chronic obstructive lung disease was 72 years (range 57-85), and the disease had been present for a mean of 20 years (range 2-50). Mean values for carbon dioxide tension and oxygen pressure were $5 \cdot 7$ (range $4 \cdot 2$ to $9 \cdot 3$ ) and $9 \cdot 1$ $(4 \cdot 9$ to $17 \cdot 1) \mathrm{kPa}$ respectively. Forced vital capacity averaged $1.8(0.6$ to 3.0$)$ litres, and forced expiratory volume in one second/forced vital capacity was $54 \%$ (28-91\%). Nine patients had clinical and electrocardiographic evidence of cor pulmonale.

No sample had evidence of haematuria, glycosuria, or lysozyme. The excretion of albumin was significantly higher in the chronic obstructive lung disease group. The distribution of $\gamma$-glutamyltransferase and $\beta-N$-acetylglucosaminidase levels was similar (figure). In the chronic obstructive lung disease group there was a highly significant relation between $\gamma$-glutamyltransferase and $\beta-N$-acetylglucosaminidase levels $(r=0.681$; $p=0.001$ ) but not between either of these levels and albumin. The excretion of these markers was not related to age, forced expiratory volume in one second, forced vital capacity, forced expiratory volume in one second/forced vital capacity, or arterial oxygen pressure, but there was a significant relation between arterial carbon dioxide tension and $\gamma$-glutamyltransferase level $(r=0.55 ; p=0.01)$. Patients with evidence of cor pulmonale did not form a distinct subgroup.

\section{Comment}

This preliminary study suggests that proteinuria may be a feature of chronic obstructive lung disease. On average the excretion was doubled, but there was a wide scatter of results; in half the patients values were normal. The appearance of albumin (a large protein) in the urine but the virtual absence of lysozyme (a small protein) suggests that the proteinuria is glomerular. A similar proteinuria has been described in chronic sleep apnoea and at high altitude. ${ }^{23}$ In both cases the protein leak was attributed to increased glomerular permeability as a result of tissue hypoxia. Whether this is so in chronic obstructive lung disease is not known.

In chronic obstructive lung disease both atrial natriuretic peptide ${ }^{4}$ and glomerular size ${ }^{5}$ are increased, which would favour increased filtration. Polypharmacy is common but the renal effect is difficult to assess and impossible to control. There was no unique combination of drugs or class of drugs associated with high renal loss of albumin or enzymes. The enzymuria may reflect tissue hypoxia, renal hypertrophy, or smoking history.

Further longitudinal studies are needed to determine whether these changes are progressive or have any prognostic relevance.

1 Daggett P. An investigation of renal function in chronic bronchitis. Postgrad Med f 1977;53:24-7.

2 Sklar AH, Chaudhery BA. Reversible proteinuria in obstructive sleep apnea syndrome. Arch Intern Med 1988;148:87-9.

3 Winterborn MH, Bradwell AR, Chessner IM, Jones GT. The origin of the proteinuria at high altitude. Postgrad Med $\mathcal{f}$ 1987;63:179-81.

4 Stewart AG, Bardsley PA, Baudouin SV, Waterhouse JC, Thompson JS, Morrice AH, et al. Changes in atrial natriuretic peptide concentrations during intravenous saline infusion in hypoxic cor pulmonale. Thorax 1991;46: 829-34.

5 Campbell LJ, Calverley PM, Lamb D, Flenley DC. The renal glomerulus in hypoxic cor pulmonale. Thorax 1982;37:607-11.

(Accepted 13 May 1993) 